\title{
PLURALISMO JURÍDICO NA SOCIEDADE DA INFORMAÇÃO
}

\section{LEGAL PLURALISM IN THE INFORMATION SOCIETY}

\author{
MARCO ANTONIO BARBOSA ${ }^{1}$
}

\begin{abstract}
RESUMO: Aborda-se a teoria clássica do Direito, concebida sob os pressupostos do evolucionismo social e sua crítica pela antropologia jurídica contemporânea, conhecida como pluralismo jurídico, ou sistemas mistos de direito, que sustenta a existência da pluralidade de sistemas jurídicos em um mesmo campo social, que o direito oficial (o Estado), nega, reconhece ou tolera, destacando as contribuições de Malinowski para a superação dos pressupostos do evolucionismo social e para um novo olhar sobre o Direito e sua adequação para a compreensão da dinâmica real do Direito na sociedade da informação.

PALAVRAS-CHAVE: Antropologia Jurídica; Evolucionismo Social; Sociedade da Informação; Ética; Crítica ao Direito.
\end{abstract}

\begin{abstract}
Approaches the classical theory of law, designed under the assumptions of social evolutionism and its criticism by contemporary legal anthropology, known as legal pluralism, or mixed systems of law, which supports the existence of plurality of legal systems in the same social field, the official law (the State), denies recognize or tolerate, highlighting the contributions of Malinowski to overcome the assumptions of social evolutionism and a new look to the law and its appropriateness for understanding the real dynamics of law in the information society.

KEYWORDS: Legal anthropology; Social Evolutionism; The Information Society; Ethics; Criticism of the Law.

SUMÁRIO: Introdução; 1. A Crítica da Antropologia Jurídica Contemporânea à Teoria Clássica do Direito; 2. Compreensão Antropológica de Pluralismo Jurídico ou Sistemas Mistos de Direito; 3. O Evolucionismo Social; 4. O Novo Olhar de Bronislaw Malinowski sobre o Direito; 5. A Definição Antropológica do Direito; 6. O Direito na Sociedade da Informação e a Utilidade para ser pensado a partir das Contribuições de Malinowski e da Antropologia Jurídica Contemporânea; Conclusão; Bibliografia.
\end{abstract}

\footnotetext{
Artigo recebido em 13.02.2012. Pareceres emitidos em 04.06.2012 e 10.06.2012.

Artigo aceito para publicação em 13.08.2012.

${ }^{1}$ Bacharel, Mestre e Doutor em Direito pela Universidade de São Paulo. Professor na Graduação e no Programa de Mestrado em Direito da Sociedade da Informação da Faculdades Metropolitanas Unidas - São Paulo. mabarbosa@fmu.br
} 
SUMMARY: Introduction; 1 . The Critique of Legal Anthropology to Contemporary Classical Theory of Law; 2. Anthropological Understanding of Legal Pluralism and Mixed Systems of Law; 3. The Social Evolutionism; 4. The New Look of Bronislaw Malinowski on the Right; 5. The Anthropological Definition of Law; 6. The Law on Information Society and Utility to be Considered from the Contributions of Malinowski and Contemporary Legal Anthropology; Conclusion; Bibliography.

\section{INTRODUÇÃO}

O objetivo deste ensaio é o de contribuir para a reflexão sobre o Direito na sociedade da informação a partir das críticas ao evolucionismo social e à teoria clássica do Direito, empreendidas pela antropologia jurídica contemporânea, denominada de sistemas mistos de direito, ou de pluralismo jurídico, segundo a qual em um mesmo campo social é possível identificar comportamentos ligados a mais de um único sistema jurídico, que o direito oficial reconhece, tolera ou nega (Griffiths, 1986, p. 1-55).

A crítica à teoria clássica do Direito inicia-se com a própria história da antropologia social moderna, especialmente com os trabalhos empíricos dos pais-fundadores da disciplina, Franz Boas e Bronislaw Malinowski. Este último dedicou-se ao estudo da Economia e do Direito nas Ilhas Trobriand, no início do século $X X$, cujas pesquisas e seus resultados teóricos tornaram-se fundamentais na Antropologia, particularmente a jurídica. Como será possível verificar no desenvolvimento do presente ensaio, as constatações de Malinowski permitiram um novo olhar sobre o Direito, diferente daquele oferecido pela teoria jurídica clássica. Esta remete o Direito necessariamente ou a um conjunto de normas advindas de um poder central ou ao processo, enquanto estrutura oficial de solução de controvérsias.

Assim, o ensaio inicialmente enfoca a teoria clássica do Direito formulada enquanto ideologia do Estado que reivindica sua unidade e o monopólio no uso da força como condição para o bem geral e a sua crítica pela antropologia jurídica. Em seguida, aborda-se a compreensão antropológica do pluralismo jurídico ou dos sistemas mistos de direito e a consequência direta que exerce sobre a noção ou o conceito de Direito, para, no item seguinte, estudar o evolucionismo social, tanto em seus aspectos teóricos quanto ideológicos e as suas aplicações e resultados políticos. Aí são focadas as críticas endereças, especialmente por Boas e Malinowiski, ao final do século XIX e especialmente no início do XX, o que produzirá a sua rejeição no campo exatamente onde foi produzida: a antropologia social, mas que, no entanto, também, como se discutirá e exemplificará, não atingiram consistentemente aos juristas e, portanto, a teoria clássica do Direito, que continuaram a se basear nos postulados falsos do evolucionismo social. No tópico seguinte, analisa-se particularmente o trabalho de Bronislaw Malinoski, intitulado Crime e Costume na Sociedade Selvagem, publicado em 1926, resultado de pesquisa de campo e de longa permanência nas Ilhas Trobriand, na Melanésia, que se tornou um clássico da literatura antropológica, tendo em vista a sua importância teórica, e suas contribuições advindas da observação direta, para um novo olhar sobre o 
Direito e que favorece ainda hoje ser tratado e percebido (o Direito) em suas relações com a realidade, com a vida do dia a dia, e não em um plano imaginário, idealizado, essencializado, como ocorre no caso da teoria clássica do Direito. Depois, é dedicado tópico para a exposição da definição de Direito de Malinowski, decorrente dessas suas observações de campo e a sua instigante utilidade para se pensar o Direito hoje na denominada sociedade da informação, o que será mais desenvolvido no item imediatamente seguinte e anterior à conclusão, que aprofunda a ideia de Direito enquanto espaço intersubjetivo e intergrupal de relações de obrigações recíprocas, na mutualidade, como Malinowski já observara nas duas primeiras décadas do século XX, onde a ética desempenha papel central.

\section{A CRÍTICA DA ANTROPOLOGIA JURÍDICA CONTEMPORÂNEA À TEORIA CLÁSSICA DO DIREITO}

Segundo a corrente mais contemporânea da Antropologia Jurídica existe pluralismo jurídico quando num campo social determinado é possível identificar comportamentos relativos a mais de uma só ordem jurídica. Assim, a coexistência do Estado e de outros grupos sociais pode ser vista sob diferentes aspectos: tanto sob o aspecto de um pluralismo concedido ou reconhecido pelo Estado, quanto como um pluralismo admitido ou tolerado pelo Estado, ou ainda como um pluralismo dirigido contra o Estado (Griffits, idem; Barbosa, 2001; p.49).

Tal compreensão revoluciona as abordagens tanto a do Direito Natural, segundo a qual o Direito decorreria da natureza das coisas, quanto do Positivismo Jurídico, segundo o qual o Direito decorreria exclusivamente da produção estatal. No entanto, em ambas essas visões a lente sob a qual é apreciado o Direito é uma só e chama-se Ocidente. Além disso, as perspectivas empregadas nessas visões são o universalismo e o evolucionismo social, como se verá ao longo da presente discussão.

Segundo essa mesma corrente doutrinária da antropologia jurídica contemporânea, os Estados modernos, com sistemas jurídicos de tipo ocidental, não podem ser os únicos modelos para o jurista pensar o Direito. Além disso, as ideias de unidade, centralidade, poder, coerção e controle, centrais nos sistemas jurídicos modernos ofuscam a possibilidade ao jurista de visualizar o Direito sem esses componentes (Barbosa, idem).

A formação jurídica ocidental sustenta-se enormemente na filosofia de Hobbes, segundo a qual sem o poder coercitivo do Estado a vida seria "grosseira, bruta e breve na guerra de todos contra todos". Porém, a antropologia moderna provou que essa visão da sociedade é em grande parte falsa, pois existem muitas sociedades sem quaisquer leis escritas, ou poder burocrático, ou violência organizada do Estado e nem por isso são sociedades sem normas de controle social ou jurídicas, ou sem mecanismos de controle social, ou sanções contra aqueles que violam essas mesmas normas. Esses mecanismos de controle social nas sociedades de tipo não estatal existem em instituições diferentes do Estado e, "o que é ainda mais importante, essas 
instituições continuam a funcionar mesmo na moderna sociedade urbana" (Shirley, 1978:9) ou na hoje chamada de sociedade da informação.

Diferentemente do que induz a crer o pensamento evolucionista aplicado à compreensão dos fenômenos sociais, o Estado com sistema jurídico de tipo moderno não significa evolução social, mas, apenas e tão somente, trata-se de um dos modelos de organização social realizado pelas sociedades que se convencionou chamar de ocidentais. O Estado é apenas um modelo, dentre os muitos historicamente realizados (Abensour, 1987, p.15-6).

A concepção ocidental do poder liga a violência ao poder, como um pressuposto praticamente universal, de modo que, para se adotar uma perspectiva comparatista de análise do fenômeno jurídico é necessário proceder à disjunção do poder e da violência, com o que, as sociedades com poder não coercitivo aparecem no mesmo nível político que as sociedades ocidentais, tão adultas quanto essas, mas de outra forma (idem).

Esta transformação dos quadros conceituais tem profundas consequências, pois, deixa-se assim de considerar como classicamente se fez as sociedades sem Estado do ponto de vista das sociedades com Estado. Isso implica nada menos, do que em uma inversão de posições, passando as sociedades com Estado - figura regional- a girarem em torno do eixo milenar das sociedades com poder não coercitivo (idem).

A todos quantos se preocupam com o Direito de forma crítica, esse tipo de questionamento induz a que se dê atenção a outros modos de juridicidade em operação. Dessa perspectiva, não se pode admitir raciocínios que digam, por exemplo, que é essencial à ideia de Direito o julgamento, ou o recurso a um terceiro para a sua aplicação, ou ainda, que a coerção é imanente ao poder e à aplicação do Direito. Na verdade, o Direito pode existir sem o Estado e este pode existir sem o Direito, no entanto, a experiência ocidental conjugou-os e os juristas, por longo tempo, identificaram o Direito com o Estado e, consequentemente, as sociedades não organizadas em forma de Estado foram julgadas como sem Direito (Rouland, 1990, p.48).

O que a antropologia e especialmente a antropologia jurídica vêm afirmando já há pelo menos um século é que as chamadas sociedades modernas, ou sociedades com Estado, não são uma evolução das sociedades tradicionais ou sem Estado, como a história do Direito ocidental costuma, sem muita crítica e sem base em dados empíricos, apresentar. Insiste ainda na necessidade de se reconhecer que o evolucionismo darwinista não serve à compreensão do fenômeno social, mas que, infelizmente, no mais das vezes, isso não tem isso sido suficientemente apreendido pelas análises e interpretações jurídicas.

\section{COMPREENSÃO ANTROPOLÓGICA DE PLURALISMO JURÍDICO OU SISTEMAS MISTOS DE DIREITO}

A partir deste ângulo de análise antropológica o Direito acaba por ser visto menos como um objeto de contornos imutáveis (como costuma ser 
apresentado pelo pensamento jurídico ocidental fortemente contaminado pelo evolucionismo social), do que apenas uma maneira de pensar as relações sociais (Rouland, 1990, idem). Essa forma de pensar o Direito e o Estado, na perspectiva ideológica do evolucionismo social, tem muitas consequências, sobretudo nos Estados, como o brasileiro, intitulados modernos, mas, de origem colonial. Nestes casos, o sistema jurídico vigente foi originariamente imposto pelo alienígena ou resultou de mimetismo jurídico por parte da classe dirigente local (Barbosa, idem, p. 31).

O evolucionismo, aplicado no campo social, marca muito o Direito de tipo moderno, excessivamente ligado à ideia de desenvolvimento, não como sinônimo de clarificação, mas de progresso, com o contorno atribuído ao termo, a partir do século XIX, diretamente ligado à medida de produção material. Desde então, o Ocidente, passou a pensar o desenvolvimento como elemento da ciência econômica, criando uma separação entre economia e cultura intelectual. Tal atitude trata-se, simplesmente, de mera escolha da cultura ocidental (idem).

A ideologia do desenvolvimento aplica-se com perfeição ao universo jurídico e consiste em considerar desenvolvidas as sociedades que adotaram as técnicas jurídicas ocidentais, onde as codificações são símbolos de desenvolvimento jurídico. Porém, no mais das vezes, esse caminho leva ao subdesenvolvimento jurídico no caso dos países periféricos e cria uma separação entre o direito oficial ocidentalizado e aplicado pela elite urbanizada e os direitos não oficiais que continuam a ser praticados pela maioria da população (idem).

Essa situação nada mais é do que o resultado do evolucionismo aplicado ao Direito e às relações entre os Estados centrais e os periféricos, levando estes ao mimetismo, que, sob a falsa imagem de progresso e desenvolvimento, gera, na verdade, o subdesenvolvimento, pela existência de uma separação entre o Direito oficial do Estado largamente desvinculado da prática social entre a maioria das populações dos países periféricos (idem).

Muito embora a antropologia e a sociologia terem já demonstrado a inexatidão de uma abordagem evolucionista da humanidade e das culturas, não é raro e é mesmo frequente ver ainda hoje os juristas utilizarem-se de explicações evolucionistas, tanto em relação ao próprio mundo ocidental quanto para se referir aos sistemas jurídicos não ocidentais. É que o ensino do Direito, de modo geral, valoriza as análises descritivas do Direito e as disciplinas teóricas acabam por ter muito pouca importância na formação jurídica. Sendo os juristas oriundos das sociedades ditas modernas ou ocidentais e devido a sua formação baseada na interpretação quase que exclusiva do sistema jurídico dessas sociedades eles acabam trabalhando unicamente com o seu próprio sistema jurídico, ignorando, no mais das vezes, as distinções dos diferentes sistemas jurídicos, o que os leva a confundir o Direito com o seu Direito. (Rouland, 1990:9) 


\section{O EVOLUCIONISMO SOCIAL}

O evolucionismo social foi a doença infantil da antropologia quando nasceu no século XVIII e serviu para legitimar as investidas européias coloniais. Ele passou por duas fases que ficaram conhecidas a primeira como evolucionismo unilinear e a segunda como neo-evolucionismo (idem). O evolucionismo unilinear, apesar de cientificamente refutado já no início do século XX no ambiente onde nasceu - a antropologia social -, inspira ainda em muito, em nossos dias, o ensino do Direito e

considera as sociedades humanas como um conjunto coerente, unitário, submetido a leis de transformação globais e genéricas, que fazem passar todas as sociedades por fases idênticas no seu conteúdo e em sua sucessão, encaixando-se umas nas outras (idem, p.15).

O evolucionismo definiu estágios, pelos quais deviam passar as sociedades antes de atingir o mais alto, às vezes designado por civilização. Morgan (Ancient Society) definiu três grandes períodos: selvageria, barbárie e civilização, divididos cada um em sub-períodos; outros introduziram as sequências: caçadores, criadores, agricultores, ou, animistas, politeístas, monoteístas. Em razão dessa classificação a sociedade moderna mais heterogénea (dividida) foi tratada em posição privilegiada, correspondente ao mais alto estágio de desenvolvimento. Contrariamente, as sociedades tradicionais foram consideradas como mais homogéneas (menos divididas) e por isso como correspondendo a estágios anteriores de desenvolvimento (idem).

No plano jurídico, o evolucionismo unilinear conduziu à separação do Direito da Moral, transferindo progressivamente a origem do grupo social (costume) para o Estado (lei), substituindo a resolução privada dos conflitos pela estatal, considerando a primeira como forma primitiva de sanção em que as próprias partes resolveriam seus conflitos e a segunda enquanto sanção civilizada pela existência de um aparelho especializado com a intervenção determinante de um terceiro (juiz, mediador, conciliador, árbitro), com bastante poder e na condição de representante da sociedade (idem, p.15-6).

Uma das principais críticas metodológicas endereçadas aos antropólogos evolucionistas unilineares é a de terem trabalhado sem jamais ter ido a campo, utilizando-se de dados de informantes, servindo-se de documentos de arquivos que refletiam mais os preconceitos do observador do que a realidade dos povos tradicionais (idem).

A partir do fim do século XIX aparecem as primeiras críticas, Franz Boas (1858-1942), antropólogo alemão e professor da Universidade de Columbia nos Estados Unidos, denunciou os "antropólogos de sofá" e as lacunas de seus trabalhos. Preferia a tais trabalhos generalistas e hipotéticos, monografias realizadas a partir de observação concreta das sociedades. Para Boas a evidência histórica só pode ser alcançada com dados empíricos, exaustivos, que permitem reconstruções seguras baseadas em fatos densamente observados. 
A reconstrução histórica é, portanto, procedimento que, pela densidade e complexidade dos dados que se acumulam sobre uma determinada realidade fecha o caminho a outras hipóteses ou a outra interpretação. É por isso que a etnografia boasiana descreve exaustivamente sem se ocupar com o estabelecimento de uma tendência da sociedade ou de uma sequência de estágios de uma sociedade. Assim, Boas se opõe ao universalismo evolucionista. A diversidade entre as sociedades é maior do que as suas similitudes (Moura, 1992).

R. Thurnwald, no campo particular da antropologia jurídica, decênios mais tarde, vem afirmar também, que uma teoria comum do Direito é praticamente impossível porque as diferenças entre as sociedades tradicionais e modernas são muito grandes (Rouland, idem, p.18).

A partir do fim da primeira década do século $X X$, aparecem novas críticas através de autores como Graebner, que compõe a escola difusionista. Graebner, por exemplo, observa os fenômenos provenientes dos contactos entre grandes círculos culturais em que as grandes culturas de um dado ponto geográfico difundem sua influência a outros, ao gosto do processo histórico, o que não ocorre com a regularidade e rigidez imaginadas pelo evolucionismo unilinear (idem, p.19).

No campo jurídico M.Scmidt (1918) e Triborn (1927), entre outros, são unânimes em rejeitar a aplicação de leis universais da história ao desenvolvimento jurídico, além de perfilharem as ideias já anteriormente esposadas por Franz Boas e por Thurnwald, de que a diversidade é maior do que a unidade entre os diversos sistemas jurídicos, bem como que, no nível metodológico, são preferíveis trabalhos de campo exaustivos e rigorosos do que teorias sobre grandes sistemas (idem, p.19).

O evolucionismo unilinear não sobreviveu a essas críticas, no campo das ciências sociais de um modo geral, se não entre os juristas, sendo que muitos deles admitem, ainda hoje, passados mais de cem anos das consistentes críticas dos antropólogos acima citados, a ideia de que a evolução conduziu as sociedades humanas da família extensa (composta de todos os descendentes de um ancestral comum, unidos pelo parentesco de sangue, dentro dos limites fixados pelo Direito, incluindo os colaterais e primos distantes e certos aliados) à família nuclear (limitada aos cônjuges e seus filhos). Esse modo de pensar é resultado das colocações dos etnólogos do fim do século XIX e começo do XX, influenciados pelo evolucionismo biológico (idem).

Claude Lévi-Strauss explica que os antropólogos evolucionistas unilienares

procuraram dispor em séries unilíneas as instituições que observavam em todo o mundo. Partindo do postulado de que as nossas eram as mais complexas e as mais evoluídas, eles viam nas instituições dos povos ditos primitivos a imagem daquelas que teriam podido existir em períodos anteriores da história da humanidade. E, uma vez que a família moderna assenta essencialmente sobre o casamento monogâmico, 
inferiram daí que os povos selvagens, assimilados pelas necessidades da causa a uma humanidade ainda na infância, não poderiam ter tido senão instituições de características exactamente opostas (1986, p. 69).

Assim, deformaram os fatos para que se vergassem às suas hipóteses, inventando pretensos estados arcaicos, a fim de caracterizar uma época bárbara.

Arrumado no lugar previsto de antemão, devidamente etiquetado, cada costume diferente dos nossos podia ilustrar uma das etapas percorridas pela humanidade desde a sua origem até aos nossos dias (idem, p.69-70).

Infelizmente, embora esse tipo de enfoque corresponda a uma fase superada e cientificamente refutada da antropologia há tanto tempo, quem é que tendo estudado Direito não se lembra do uso recorrente de uma quase obrigatória, ritual e mítica primeira parte de diversas disciplinas, pretensamente de caráter histórico, onde, inevitavelmente consta um: "nos primórdios da humanidade..."? Nesses tais "primórdios da humanidade" tudo é reduzido a uma única história humana, porém hipotética. Refere-se sempre a um estágio menos "evoluído" do que outros posteriores, até chegar ao modelo atual ocorrente na sociedade moderna e que, quase que invariavelmente, é enfocada como o ápice de uma também hipotética cadeia evolutiva.

Esse tipo de abordagem é muito recorrente entre os juristas, sobretudo no que se refere ao direito de família, ao direito relativo aos contratos e ao direito penal, apenas para citar os exemplos mais evidentes. A análise evolutiva do Direito apresenta a família como tendo sido extensa nos tais chamados "primórdios da humanidade", que teria caminhando com "o passar dos tempos" à "família nuclear monogâmica".

Outros pontos, nos quais não raro a interpretação evolucionista habita as análises e interpretações jurídicas referem-se ao contrato e à propriedade. É que o evolucionismo costuma enfocar o contrato como uma evolução do status. Desse modo o contrato estaria para a sociedade moderna, assim como o status para a tradicional. Os direitos e obrigações do indivíduo nos mesmos tais "primórdios da humanidade" seriam definidos por sua condição estatutária dentro do grupo social, o que significaria que no "passado da humanidade" teria havido, como igualmente haveria no presente das chamadas sociedades tradicionais, um imobilismo social, determinado pelo status, enquanto que as sociedades modernas se caracterizariam pela mobilidade e dinâmica do contrato (Lévi-Strauss, idem, p. 75-98 e Rouland, idem, p. 22-3).

De fato, o que as pesquisas posteriores ao evolucionismo social revelaram a partir da observação rigorosa da realidade das sociedades tradicionais é que tais categorias não se excluem. Ao contrário, tanto nas sociedades modernas quanto nas tradicionais coexiste o status com o contrato, não havendo a predominância de uma dessas categorias sobre a outra, em sucessão diacrônica (no tempo), como quer o evolucionismo social. Assim, não se trata de uma 
"lei histórica" a prevalência do contrato ou do status, mas, sim, apenas e tão somente, a escolha de um projeto social, desta ou daquela sociedade. $\mathrm{O}$ fato de o contrato ser mais valorizado em sociedades como as chamadas de modernas, revela, simplesmente, que essas sociedades privilegiam o indivíduo ao grupo, sem que isso possa significar condição de evolução dessa sociedade em relação às tradicionais que, ao contrário, privilegiam o grupo ao indivíduo. De qualquer modo, o contrato existe também nas sociedades tradicionais, como também, o status nas modernas, embora estas privilegiem o contrato, ao menos ideológica e discursivamente. A despeito de tal ideologia que sustenta a prevalência do contrato, o status desempenha papel não desprezível nas chamadas sociedades-modernas (idem).

No caso da propriedade, também, em geral, os civilistas acompanharam o evolucionismo unilinear, praticamente sem qualquer crítica, o que demonstra, em última análise, que eles próprios sequer conhecem a "evolução" do pensamento antropológico que determinou as suas afirmações. Frequentemente sustentam que primeiro teria existido a propriedade coletiva do clã, seguida pela familiar e por último a individual. Veja-se o que diz o respeitável Washington de Barros Monteiro: "Parece que a propriedade nos "primórdios da civilização" começou por ser coletiva, transformando-se, porém, paulatinamente, em propriedade individual (Monteiro, 1977, p. 85)" (g.n.).

Essa ideia possuiu um corolário que opõe a concepção civilista original do direito da propriedade imobiliária, concebido como imprescritível, absoluto, exclusivo e perpétuo, ao direito costumeiro, taxado de arcaico, que consideraria a terra como um bem imóvel sobre o qual pesaria um direito coletivo de propriedade, tornando-o inalienável e qualificando os direitos imobiliários de temporários, limitados e relativos (Rouland, idem, p. 23).

Tal construção evolucionista é passível de várias críticas. Primeiro por seu caráter arbitrário, porque essa simplista reconstrução trata como se existisse uma sucessão cronológica, quando na verdade o que existe são realidades jurídicas sincrônicas. Não há como essa forma de analisar sugere passagem de direitos coletivos para individuais, de acordo com o que os estudos de campo em antropologia demonstram. Na verdade, o que ocorre, é sua coexistência (idem).

No direito penal a situação não é diferente, como demonstra a lição do Professor Basileu Garcia (1972, p. 12), que diz:

Em tempos remotos da história da humanidade, época houve em que o homem fazia justiça pelas suas próprias mãos. Era a vingança privada, violenta e quase sempre eivada de demasias. Sem observar, mesmo aproximadamente, a lei física da reação igual e contrária à ação, o ofendido e os do seu agrupamento procediam desordenada e excessivamente, de modo que, às vezes, aquilo que constituía ofensa a um indivíduo passava a sê-lo relativamente à comunidade toda a que ele pertencia, travando-se lutas e guerras que o ódio eternizava". 
Tal abordagem, quem tendo estudado Direito no Brasil, não a ouviu e até mesmo não acredita nela como sendo uma "verdade verdadeira", por ter sido sempre tão usual e recorrente? Simplesmente, trata-se, na verdade, de mais uma abordagem evolucionista, que descreve a pena estatal como sendo uma reação do corpo social inteiro, em geral aplicada por uma autoridade que representaria esse corpo social inteiro, contra o autor da infração, cujo efeito seria regulador e benéfico para a sociedade. Note-se que no caso, sociedade, também, falsamente referida como unitária e coesa. Nesse tipo de discurso, mais ideológico do que científico, são realçadas as tintas que dão a falsa ideia da progressão linear. Contrapõe, para sustentar o argumento, a forma de solução privada dos conflitos e denominando-a de vingança e caracterizando-a como reação imediata a uma infração, apontada em geral como desmedida, praticada por um indivíduo ou grupo, porém, sempre na perspectiva de que seria prejudicial à ordem social. Assim, seria duplamente negativa: selvagem e arcaica (Rouland, idem, p. 27).

Na continuação desse modo evolucionista de apresentação da "evolução do direito penal", em seguida à vingança, viria, inevitavelmente, a pena de talião, por sua vez, finalmente, sucedida pela solução legal, ocorrente, como não poderia deixar de ser, nas sociedades que batizaram de civilizadas, onde o Estado, a título exclusivo encarregar-se-ia da reparação, através do sistema de penas públicas, pronunciadas e executadas em nome da sociedade. Essa é a sucessão evolutiva adotada em geral, pelos criminalistas que, grosso modo, a despeito das mais modernas pesquisas antropológicas em sentido contrário, mantêm-se inalterada no imaginário jurídico (idem).

Diferentemente desse simplismo até ingênuo, vários estudos de antropologia social demonstram que o instituto denominado vingança, contrariamente ao sustentado pelos criminalistas, obedece à minuciosa regulamentação, é limitado e não se aplica contra membros do próprio grupo, a fim de evitar o seu desmoronamento. Internamente ao grupo os conflitos são geralmente resolvidos pacificamente: combates rituais, sacrifícios, conciliações, ou mesmo penas. A vingança nesses contextos só é possível entre grupos diferentes e requerer procedimentos específicos que objetivam evitar excessos e se situa antes no campo de relações políticas entre grupos diferentes do que no campo penal interno ao próprio grupo social (Ramos, 1986, p. 64-5 e Rouland, idem, p. 27-8).

$\mathrm{Na}$ verdade, esse tipo clássico de apresentação sequencial (históricohipotética) conduzindo da vingança (arcaica) à pena (civilizada), provavelmente decorre de uma visão moderna, posterior à instauração do Estado e serve para legitimar a sua reivindicação de monopólio da violência e da sanção (Rouland, idem).

Ao afirmar que a humanidade tem em si disposições imanentes que se desenvolvem à medida em que a sociedade progride o evolucionismo social despreza a diversidade das instituições, inclusive jurídicas, que são, 
na verdade, determinadas em suas formas particulares em razão da sua localização sociológica em cada uma das sociedades, especificamente consideradas. O equívoco do evolucionismo social consiste em sustentar que o desenvolvimento se faria essencialmente segundo uma mesma linha diretriz em todos os níveis da cultura e que seria aplicável a todas as sociedades da mesma forma. Na verdade e como já anteriormente dito a apresentação evolucionista se sustenta em uma história que não é real, mas meramente hipotética (Panoff \& Perrin, 1976).

É preciso ficar claro, porém, que ao se refutar o evolucionismo não se está negando a universalidade de mudança cultural. É claro que todas as sociedades conhecem processos adaptativos. O defeito do evolucionismo é ter apresentado de forma muito sistemática descrições parciais ou mesmo caricaturais das sociedades, as quais dificilmente se enquadram no quadro definido. Isso porque é muito grande o número de variáveis fáticas que impedem a aceitação de um método que pretende fazer um estudo global privilegiando certas linhas da evolução (idem).

O fato é que a história não é igual para todas as sociedades e nem tampouco imóvel. A história, na verdade, influencia a realidade sociológica e a visão que as sociedades têm de si mesmas. É por causa dessa sua história específica, de sua relação com o meio ambiente onde vive e das representações mentais que constitui sobre si mesma que uma sociedade apresenta-se deste ou daquele modo, em um determinado presente. É isso tudo que também vai determinar a adoção destas ou daquelas instituições, de acordo com a época e o lugar. $\mathrm{Na}$ verdade, não existe princípio geral, diligência dedutiva, que permita antecipar os acontecimentos contingentes de que é feita a história de cada sociedade, nem as características particulares dos ambientes onde se localiza. Tampouco, as significações imprevisíveis que cada sociedade acaba dando a tal ou qual aspecto do seu habitat, entre todos aqueles que muito bem poderia ter escolhido para conferir-lhe um sentido (Lévi-Strauss, idem, p. 15).

Assim, cada cultura é uma ocorrência única e apenas por meio do seu exame específico é possível conhecer os fatos e os critérios, variáveis de uma cultura para outra, em virtude dos quais cada uma delas fez determinadas escolhas, dotando-as de significação e organizando em forma lógica um conjunto acabado de elementos. Um específico tipo de organização, que compõe um conjunto dotado de significado, resulta de certas orientações históricas e de certas propriedades do meio ambiente combinadas com as exigências mentais da sociedade em questão (idem).

As sociedades que não adotam o tipo organizativo do Estado ocidental oferecem-nos um exemplo de experiência política diferente, o que implica em uma complexidade nova no espaço político, porque o espaço político ocidental, posto e pensado como universal, nada mais é do que, apenas, uma modalidade regional de realização política, de modo que o espaço político não 
pode ser representado como uma gradação contínua de sociedades sem Estado, em direção a sociedades com Estado. Não se trata, pois, de uma lenta subida progressiva em direção ao Estado. Trata-se de um espaço irredutivelmente descontínuo (Abensour, 1987, p.16).

Com isso, há evidentemente uma transformação em nossos quadros conceituais que requer uma nova interpretação. Não se pode mais opor as sociedades sem Estado às sociedades dotadas de Estado. Deve-se substituir essa oposição por outra nova, qual seja: sociedades com poder coercitivo centralizado e sociedades sem poder coercitivo centralizado ou discreto (idem).

O fato importantíssimo desprezado na abordagem de tipo históricohipotético é que cada cultura, cada sociedade, é uma ocorrência impar que não permite generalização. Apenas o exame específico de uma específica sociedade, uma específica cultura, é que poderá descortinar quais foram os fatos e os critérios em virtude dos quais ela fez determinadas escolhas, atribuindo a essas escolhas significado e organizando de forma lógica um conjunto acabado de elementos (Lévi-Strauss, idem).

\section{O NOVO OLHAR DE BRONISLAW MALINOWISKI SOBRE O DIREITO}

$\mathrm{Na}$ antropologia social e jurídica Bronislaw Malinowski (1884-1942) foi certamente quem mais enfaticamente reagiu às explicações de tipo histórico. Juntamente com Franz Boas é reconhecido como um dos fundadores da moderna antropologia de campo. Para o Direito suas ideias são extremamente importantes, sobretudo por insistir sobre a necessidade da pesquisa empírica, o que reaproxima o Direito da realidade, em razão do fato de que ele não consiste apenas de normas abstratas, mas também, de fenômenos concretos que podem ser observados de forma direta. Além disso, sustenta que para ser compreendida uma instituição ou qualquer fato social, os mesmos precisam ser analisados de forma holística, ou seja, em suas relações com as demais instituições e fatos. Isso impõe a conclusão de que o Direito é também dependente das outras partes que compõem o todo social, tais como a economia, a cultura, a biologia, entre outras (Rouland, idem, p. 35-6).

Seu trabalho intitulado Crime e Costume na Sociedade Selvagem, resultado de suas pesquisas de campo nas Ilhas Trobriand, publicado em 1926, tornou-se um clássico da antropologia moderna. Trata-se de importante obra para o estudo do Direito, porém, no campo desta disciplina é pouco conhecida e explorada. Entre muitas outras qualidades, esse estudo desfaz muitos mitos evolucionistas que até então vigoravam sobre as então chamadas sociedades primitivas, especialmente no que se refere ao Direito.

No primeiro item da Parte $I$, intitulado "A submissão automática ao costume e o problema real" (2008; p.15), Malinowski parte das afirmações correntes na antropologia de sua época que sustentavam que o "selvagem"

tem uma profunda reverência pela tradição e o costume, numa submissão automática às suas ordens. Ele obedece a elas "servil", "involuntária" e 
"espontaneamente", por "inércia mental", associada ao temor da opinião pública ou de castigo sobrenatural, ou por meio de um "penetrante sentimento de grupo" quando não "instinto de grupo.

Ele responde a essas afirmações sustentando que sociedade alguma, seja ela "civilizada" ou "selvagem", pode funcionar eficientemente se as leis não forem obedecidas de modo "voluntário e espontâneo" e que a ameaça e o medo de punição "não afetam o homem comum, seja ele selvagem ou civilizado, enquanto que, por outro lado, são indispensáveis em qualquer sociedade em relação a certos elementos turbulentos ou criminosos" (idem, p. 17-18). E acrescenta:

Além disso, há um certo número de leis, tabus e obrigações em toda cultura humana que muito pesa sobre todos os cidadãos, exigindo grande auto-sacrifício, que é obedecido por razões morais, sentimentais ou reais, embora sem qualquer "espontaneidade" (idem, p. 18).

Apenas nessas poucas linhas Malinowski produz mudanças conceituais de largo alcance. Em primeiro lugar, desfaz a separação artificial forçada entre "Nós" e "Eles", ou entre "Civilizados" e "Selvagens". Em segundo lugar, iguala as chamadas sociedades civilizadas e as selvagens ao acentuar que a voluntariedade e a espontaneidade na obediência à lei é o que mais ocorre em qualquer tipo de sociedade. Em terceiro lugar, e por via de consequência, sustenta, também, que para a grande maioria da população, de qualquer sociedade, não são a ameaça ou o medo de punição que fazem as pessoas agir conforme ao Direito voluntária e espontaneamente. A ameaça e o medo têm destinatários precisos: os "turbulentos e criminosos" em qualquer sociedade, seja "civilizada" ou "primitiva". Em quarto lugar, sustenta também que em qualquer tipo de sociedade haverá certo número de normas que são obedecidas por razões morais, sentimentais ou reais, embora sem qualquer espontaneidade e isso independentemente de ser a sociedade "selvagem" ou "civilizada".

Sustenta ao final desse mesmo tópico que a "lei não é imposta por nenhum motivo indiscriminado, como o medo da punição ou a submissão geral a todas as tradições, mas por incentivos psicológicos e sociais muito complexos" (idem, p. 18).

Como já anteriormente mencionado, a pesquisa que resultou nessa obra desenvolveu-se nas Ilhas Trobriands, habitadas por comunidade melanésia e situada a nordeste da Nova Guiné, consistindo em um grupo de ilhas de coral planas, em torno de uma ampla laguna. Essas ilhas sustentavam já à época de Malinowski uma densa população, envolvida principalmente na agricultura e na pesca e dedicada ao comércio e ao intercâmbio. Sistemas tecnicamente precisos para a pesca, complexos arranjos econômicos, boa organização das equipes de trabalho e divisão de funções sociais foram identificados pelo pesquisador. Identificou também claramente um sistema de propriedade das 
canoas de pesca aliado ao trabalho da tripulação, de modo que apesar de proprietário da canoa o mesmo não podia recusar o uso da mesma quando a comunidade saia para pescar. O conjunto desses homens (tripulação) e o proprietário da canoa, em geral, pertencem ao mesmo subclã e assim encontram-se ligados entre si por obrigações mútuas. De modo que, por ocasião de uma pescaria, ou o proprietário da canoa compõe ele próprio o grupo ou indica alguém para substituí-lo. "Na distribuição do resultado da pesca, cada homem também recebe a justa parte, equivalente a seu trabalho" (idem, p. 21).

Malinowski observa que nessa atividade econômica de pesca das Ilhas Trobriands "há um sistema definido de divisão de funções e um sistema rígido de obrigações mútuas, em que um sentido de dever e de reconhecimento da necessidade de cooperação entram, lado a lado, com a verificação do interesse próprio, dos privilégios e dos benefícios" (idem, p. 23). Desse modo "a propriedade não pode, pois, ser definida por expressões como "comunismo", "individualismo", nem por referência ao sistema de "cooperativas" ou de "empresa privada", mas pelos fatos concretos e pelas condições de uso. É a soma de deveres, privilégios e reciprocidades que liga os sócios-proprietários entre si e ao objeto" (idem).

Conclui, portanto, que em relação à canoa nativa, o que encontrou foi "a ordem, a lei, os privilégios definidos e um sistema de obrigações bem desenvolvido" (idem).

Incrementando a sua atenção à força das obrigações econômicas, no título III da Parte I, Malinowski observa a divisão do produto da pesca. Relata que residentes do interior das Ilhas, normalmente, estão aguardando o retorno dos pescadores e recebem lotes de peixes e os levam para suas casas. E acrescenta:

Aqui mais uma vez encontramos um sistema de serviços e de obrigações mútuas baseado em um acordo permanente entre as duas comunidades. A aldeia do interior fornece legumes e verduras aos pescadores, e a comunidade costeira paga em peixes. É um acordo basicamente econômico. Há também um aspecto cerimonial na troca, a qual deve ser feita segundo um complexo ritual. Além disso, existe ainda o aspecto legal, um sistema de obrigações mútuas que força o pescador a retribuir sempre que recebe um presente do parceiro do interior e vice-versa. Nenhum dos parceiros pode recusar um presente, ser parcimonioso com seu presente de volta e nem pode se atrasar (idem, p. 25).

Trata-se no caso estudado, na verdade, de um sistema que valoriza o alimento respectivamente mais raro. No entanto, a isso é acrescentada "uma dependência artificial e culturalmente criada de um distrito sobre o outro" e se houver negligência no cumprimento da obrigação por uma das comunidades "serão severamente castigados. Portanto, cada comunidade tem uma arma para fazer cumprir seus direitos: a reciprocidade" (idem, p. 26). 
Assim, uma das mais importantes contribuições para um novo olhar sobre o Direito, decorrente das observações de Malinowski sobre as relações sociais e econômicas das llhas Trobriands, foi identificar a reciprocidade como a principal razão da obediência ao Direito, pois, no caso específico de suas observações empíricas, a troca de peixes por vegetais mostrou-se à evidência como a razão econômica fundamental. Porém, a reciprocidade atinge ainda outras formas de comércio e serviços mútuos, também por ele observados, constituindo-se em uma cadeia de reciprocidade reforçada pela diversidade de mutualidades em operação (idem, p. 26).

Além disso, Malinowski desfaz muitos outros mitos até então existentes sobre o comportamento "mecânico" dos povos "selvagens" e sua obediência "cega" aos costumes, bem como de que existiria nessas sociedades preeminência de regras penais e ausência ou pouca evidência das civis. Afirma o antropólogo:

Compreendemos agora como as regras da lei, regras de caráter inequivocamente obrigatório, sobressaem às regras simples dos costumes. Podemos também ver que a lei civil, consistindo em disposições categóricas, é muito mais desenvolvida do que o conjunto das simples proibições e que o estudo exclusivo da lei criminal entre os selvagens omite os fenômenos mais importantes de sua vida legal (idem, p. 30).

Acrescenta ainda que tais regras não têm o caráter de mandamentos religiosos estabelecidas de modo absoluto e obedecidas rígida e integralmente. Ao contrário, elas são elásticas e ajustáveis, havendo, portanto, espaço considerável no qual seu cumprimento é considerado satisfatório (idem, p. 30-31). Tal percepção da "lei" coaduna-se com a concepção da mais recente teoria da antropologia jurídica segundo a qual as normas não são estáticas porque podem ser negociadas antes, durante e mesmo depois da decisão e isso em qualquer sistema jurídico, seja tradicional ou moderno. Desse modo, a pesquisa empírica de Malinowski e suas observações e teorizações podem servir como lições básicas sobre o Direito, independentemente de se tratar de sistemas jurídicos de base ocidental. É que ele mostra que o principal aspecto da efetiva coação social ao cumprimento da lei encontra-se "nos complexos arranjos que fazem as pessoas se aterem as suas obrigações. Entre eles, o mais importante é o modo como muitas transações estão ligadas em cadeias de serviços mútuos, cada um dos quais terá de ser pago mais adiante" (idem, p. 31). Ele inclui a publicidade das relações contratuais, a ambição e a vaidade, como outros importantes fatores para reforçar o cumprimento da lei, no caso dos melanésios.

Assim, sua observação até aqui mencionada ressaltou a igualdade entre "civilizados" e "selvagens" no que se refere à lei civil que "basicamente se ocupa com a propriedade e com a riqueza" (idem, p. 33). No entanto, na sequência, dedica-se em desvelar como o Direito também se mostra presente nos atos religiosos. Por ser a sociedade melanésia matrilinear, ou seja, onde 
os direitos são transmitidos pela linha materna, além dos aspectos religiosos envolvidos, por exemplo, nos ritos de luto e pesar pelos mortos, há outros que dizem respeito diretamente ao Direito. Desse modo, a esposa do falecido tem o dever para com os sobreviventes da família do esposo de manifestar mortificação e de guardar um longo período de luto. Tal obrigação tem a sua contrapartida, a sua retribuição. É que, três dias após a morte de seu marido, a viúva receberá dos parentes do falecido um pagamento ritual, além de outros pagamentos posteriores. Trata-se de um elo na cadeia vitalícia de reciprocidade entre marido e mulher e entre as suas respectivas famílias (idem). Da mesma maneira, as relações matrilineares impõem ao irmão deveres para com a irmã e seus filhos. Na colheita dos inhames, principal produto agrícola da sociedade trobriandesa, a melhor parte deve ser destinada à casa da irmã, depois de exposta aos olhos de todos. Explica Malinowski que todo o lado cerimonial da transação opera como força de aglutinação e a avaliação pública impõe sobre o doador uma coerção psicológica, satisfazendo-o e gratificando-o, "quando um trabalho bem-sucedido lhe permite dar um presente generoso, ou o penalizam e humilham, quando há ineficiência, mesquinharia, ou falta de sorte" (idem, p. 36).

Segundo o antropólogo, na sociedade que estudou, do ponto de vista legal e do ponto de vista econômico, o sistema é baseado em concessões mútuas bastantes complexas e que no longo prazo os serviços mútuos se equilibram. Além disso, a verdadeira razão do respeito a essas mutualidades

é que a falta de cumprimento deixa um homem em posição intolerável e a tibieza em seu cumprimento cobre-o de opróbrio. O homem que persistentemente desobedece às regras da lei em seus tratos econômicos, logo se encontra fora da ordem econômica e social - e ele tem perfeita consciência disso (idem, p. 38).

\section{Constata que}

o cidadão honrado deve cumprir seus deveres. Porém, não há nisso participação de qualquer idéia relacionada a "instinto", "impulso intuitivo" ou misterioso "sentimento de grupo". Os direitos não são, pois, exercidos arbitraria e unilateralmente, mas segundo regras definidas, arranjadas em cadeias muito bem equilibradas de serviços recíprocos. Até mesmo o chefe deve conformar-se a normas rígidas e sofre restrições legais (idem, p. 41).

Malinowski, na verdade, em tal trabalho, procurou diferenciar as normas legais das costumeiras. Estas, fortemente respeitadas, podem ser compreendidas como aquilo que todos fazem, o que todos aprovam. Assim,

se não for direcionado ou impelido a outro rumo pelos próprios desejos ou interesses, seguirá as ordens do costume e não qualquer outra direção. A força do hábito, a reverência pela autoridade tradicional e um apego 
sentimental a isso, o desejo de satisfazer a opinião pública - tudo se combina para fazer com que o costume seja obedecido pelo próprio mérito (idem, p. 44).

Segundo seu raciocínio, nem todas as regras sociais são legais, ao contrário, as regras da lei constituem-se, portanto, em "apenas uma categoria bem definida no conjunto dos costumes" (idem, p. 45). Vejamos, então, a seguir, a definição antropológica da lei (direito), apresentada por Malinowski.

\section{A DEFINIÇÃO ANTROPOLÓGICA DO DIREITO}

Constituem-se em legais aquelas e apenas aquelas normas que são experimentadas e consideradas enquanto obrigações de uma pessoa e justos direitos de outra (idem, p. 47), sua força compulsória decorre da dependência mútua que se realiza no "arranjo equivalente de serviços recíprocos e na combinação desses direitos em correntes de relacionamento múltiplo" (idem). O mecanismo compulsório é notoriamente reforçado pelo fato de a lei estar, na maioria das vezes, sujeita à crítica e ao controle público, razão pela qual as transações legais ocorrerem, também em sua maioria, com obediência a certas formalidades (idem).

Malinowski define assim a lei civil (no caso das Ilhas Trobriand) como o conjunto de normas formais de obrigações, que regem todas as fases da vida, consideradas adequadas por um grupo e reconhecidas como dever pelo outro, mantida em vigor pela reciprocidade e publicidade inerentes à própria estrutura social.

Igualmente, a norma jurídica caracteriza-se pela elasticidade e por certa amplitude e não apenas prevê penalidades em caso de violação, mas, também, premia quando do seu exemplar cumprimento. É a avaliação racional de causa e efeito que assegura o seu rigor, "aliada a uma série de sentimentos sociais e pessoais, como a ambição, a vaidade, o orgulho, o desejo de aperfeiçoamento pessoal pela exibição, além de apego, amizade, dedicação e lealdade aos parentes" (idem, p. 49).

Além disso, Malinowski acrescenta finalmente que a lei, ou Direito, não se trata de um lócus especial pairando acima ou à parte da sociedade e de seus demais elementos constitutivos. Portanto, não pode ser compreendido como um conjunto especial de regras "que prevê e define possíveis formas de contravenção e provê barreiras e reparos apropriados" (idem). O Direito é, pois, resultado da configuração de obrigações recíprocas que impossibilitam o cidadão de se esquivar às suas responsabilidades sem que com isso sofra as consequências no futuro (idem).

6. O DIREITO NA SOCIEDADE DA INFORMAÇÃO E A UTILIDADE PARA SER PENSADO A PARTIR DAS CONTRIBUIÇŐ̃ES DE MALINOWSKI E DA ANTROPOLOGIA JURÍDICA CONTEMPORÂNEA

A sociedade da informação, também chamada de pós-industrial ou pós-moderna, de modo bastante sintético, pode ser compreendida como a 
contemporaneidade onde a informação, bem intangível, constitui-se no maior valor e é produto do esforço intelectual que não depende de qualquer base material. Nesse cenário, o poder é difuso e disperso.

Essas características básicas da contemporaneidade têm evidentes consequências jurídicas e erodem as formulações da teoria clássica do Direito, construídas ao tempo da instauração do Estado-Nação moderno, como ideologia e discurso sustentadores de um pretenso monopólio da produção e sanção do Direito em nome da sociedade, tratada como unidade.

No mundo globalizado, onde a economia aumenta sua autonomia em relação às instituições e aos mecanismos de controle social e as interações e vínculos intersubjetivos e intergrupais são trans-fronteiriços e frequentemente virtuais, a soberania, entendida como limites geográficos e humanos do poder estatal, sobre os quais o Direito legiferado pelo parlamento e a jurisdição oficial exercer-se-iam com base em competência constitucionalmente estabelecida de forma uniforme e absoluta, não mais responde satisfatoriamente ao mundo real. Ao contrário, nesse novo ambiente a vida social não é mais regulada pelo direito positivo. Isso fica muito evidente com o

papel crescente que ganham os contratos com relação às leis, a extensão dos mecanismos de arbitragem e de mediação e sobretudo a neutralidade crescente da lei em domínios tão importantes quanto à vida familiar ou o comportamento sexual, sem mencionar o enfraquecimento das normas, mais fácil de observar, nos domínios mais individuais de comportamento, como alimentação e vestuário (Touraine, 1998, p. 91).

É evidente, pois, que a realidade na sociedade da informação encontra-se muito distante das concepções liberais e revolucionárias de democracia (Touraine, idem, p. 97) que falavam do

curso da história, como se fosse uma história que se narra, que tem um começo e um fim, e a sociologia definia uma sociedade, uma instituição, uma personagem, por seu grau de modernidade, por seu lugar numa escala indo do tradicional ao moderno, da reprodução à produção, do status ao contrato, do holismo ao individualismo (idem. p. 99).

É que, como afirma Touraine, a globalização das trocas torna simultâneo o que era sucessivo. Ela também obriga a que se abandone a identificação ingênua com o progresso, com a modernidade, com o universal, como pensados pelo evolucionismo social. O presente impõe a necessidade de mudança na maneira de combinar formas de vida social e cultural que não podem mais ser separadas por etapas de um progresso unilinear, como sugere Touraine e como já em 1926 as pesquisas de Malinowski anteciparam.

O presente da sociedade da informação exige concepções mais elaboradas de Direito e o abandono de sua tradicional definição positivista "como ordem coativa constituída à base de normas, as quais formam uma 
unidade que não apenas reserva para si o monopólio da força nas relações sociais, como igualmente regulamenta as relações fundamentais para a convivência e supervivência dos grupos sociais" (Faria, 1986, p. 168).

José Eduardo Faria acrescenta que os novos paradigmas exigem a busca de um Direito enquanto conjunto de regras em movimento e continuamente reformuladas, inclusive por forças extra-legislativas e extra-estatais. Desse modo o próprio objeto da Ciência Jurídica é deslocado, não se encontrando mais no conjunto de normas instituído em dogmas, mas, exatamente, nos próprios fatos sociais (idem).

\section{CONCLUSÃO}

As lições de Malinowski são muito atuais e antecipam o que teóricos da pós-modernidade viriam constatar décadas mais tarde, como Ernest Laclau (apud John Lechte, 2002, p. 212) que afirma que nenhuma estrutura social é inteiramente fechada e que o deslocamento é a porta para a ação transformadora.

Igualmente, os teóricos contemporâneos e críticos do Direito, não deixaram de perceber que a normatividade jurídica e a estatização da resolução de conflitos, como nortes da ciência jurídica, não mais se sustentam na sociedade da informação e no mundo globalizado, caracterizados essencialmente pela "diferença", atravessada por diferentes divisões e antagonismos sociais que produzem variedade de diferentes posições dos sujeitos (Faria, idem).

Nesse quadro, o próprio pensamento democrático, antes pensado como dizendo respeito ao futuro - profético-, torna-se um meio de combinar presente e passado e defende a liberdade contra todos os poderes: econômicos, políticos e culturais e não se dirige a qualquer porvir glorioso, mas, para a reconstrução de um espaço de vida pessoal e de mediações políticas e sociais que a protegem (Touraine, idem, p. 103-4). Por conseguinte, o Direito na Sociedade da Informação, tem a ver, essencialmente, com a ética e a responsabilidade.

Não é exatamente nesses termos que Malinowski percebe o Direito enquanto espaço de mutualidades e de obrigações recíprocas? A mutualidade dessas obrigações e a publicidade de que se revestem não são o que, na verdade, garantem a sua validade e respeito, reforçadas por aspectos sociais e pessoais, tais como a ambição, o orgulho, a exibição, a amizade, a dedicação e a lealdade? Não será também nesse mesmo sentido que se deve perceber o Direito real na sociedade da informação, enquanto campo de relações, marcado por profundas diferenças, sem referência necessária e obrigatória a um centro de poder (o Estado) do qual emanaria um sistema substancial de normas gerais, abstratas e cogentes, mas, sobretudo, enquanto campo dinâmico de relações intersubjetivas e intergrupais, onde as regras estão em permanente movimento, com origens e criações diversas, sujeitas a negociações, transações, avaliações e reajustes, com possibilidades de sempre novas articulações e continuamente reformuladas, até mesmo por 
forças extra-legislativas e extra-estatais? Não é exatamente a mutualidade, de que já falava Malinowski, a única garantia de que se pode viver em um mundo do Direito, embora não mais apenas e necessariamente positivista? Enfim, nessa perspectiva, a ética, ao fim e ao cabo, não é a principal referência do Direito na Sociedade da Informação?

O evolucionismo, que está na base do pensamento da teoria clássica do Direito, é simplista e incapaz de lidar adequadamente com o fato de que cada fenômeno, inclusive jurídico, é uma trama de relações, e não uma única substância. Sendo assim, é necessário integrar o relativismo para compreender o percurso do Direito feito de invenções, é certo, mas também de erros e desvios. Ele não pode ser mais identificado ou postulado como conjunto de normas emanadas de um poder central ou pelos meios oficiais de resolução de conflitos, porque, o mundo presente, o mundo da sociedade da informação é atravessado pela complexidade e pela diferença. Diferença não enquanto outra identidade qualquer, nem enquanto diferença entre duas diferenças. Trata-se aqui da diferença no sentido cunhado por Derrida (apud Lechte, p. 126-7). Esta é sempre impura e por isso desafia a ideia de identidade, não sendo, portanto, fenomenal, mas, sim, virtual. Não se trata do que é produzido, mas o que permite a produção, pois todo essencialismo, ou teleologia, versão do idealismo, tem, como já afirmou Nietzsche, que negar um ou mais aspectos da vida para ganhar alguma coerência. O Direito, assim como a vida é irredutível. É uma totalidade de diferenças e não uma identidade.

O conceito de Direito como forma de unidade (enquanto conjunto de normas emanadas e sancionadas por um poder central, por exemplo) perdeu qualquer credibilidade, pois esse modo de apreensão trata-se de uma metanarrativa, que como qualquer outra se relaciona com a identidade e não com a diferença e, portanto, com a idealidade, o essencialismo que como qualquer outro nega a vida.

Direito já na experiência de campo e na lição de Malinowski, assim como na sociedade da informação, antes de tudo é fato da vida e não está ligado a qualquer plano ideal. Não se define por qualquer conjunto dado de regras emanadas de um poder central ou por um específico mecanismo de solução de conflitos, por meio da intervenção determinante de um terceiro, na condição de juiz, arbitro mediador ou conciliador, mas se constitui dos próprios fatos sociais e não pelas diferentes modalidades pelas quais pode ser representado (sistema de normas ou processo). A reciprocidade é que permite a vida social e liga os indivíduos e os grupos e não a sanção ou a ameaça de sanção, advinda de uma autoridade central e ela, a reciprocidade, não tem antes de tudo a ver com a ética?

$\mathrm{O}$ Direito, nesses termos, diz mais respeito à diferença do que à identidade. Deve ser compreendido também como complacente e dotado de certa amplitude, dado que mesmo as normas, até mesmo as estatais, não são 
estáticas, estando sujeitas a negociações entre as partes, durante e mesmo depois do conflito ou mesmo da decisão. É também, como diz Malinowski, sujeito à avaliação racional de causa e efeito pelos próprios envolvidos nas relações obrigacionais mútuas e não é imune aos efeitos dos sentimentos humanos (ambição, vaidade, orgulho, entre outros), os quais contribuem para a sua maior eficácia.

\section{BIBLIOGRAFIA}

ABENSOUR, Miguel. Presentation. In: Abensour, Miguel et al. L'esprit des Lois Sauvages. Paris, du Seuil, 1987.

BARBOSA, Marco Antonio. Direito Antropológico e Terras Indígenas no Brasil. São Paulo: Fapesp/Plêiade, 2001.

BARBOSA, Marco Antonio. "Pós-Modernidade: a identidade real ou virtual?". Direitos Culturais, Santo Ângelo, v. 5, no 8, jan./jun. 2010, p. 75-92.

FARIA, José Eduardo. Eficácia Jurídica e Violência Simbólica. São Paulo: Edusp, 1986. GARCIA, Basileu. Instituições de Direito Penal. Vol. 3, 4. ed., São Paulo: Max Limonad, 1972.

GRIFFITHS, John. "What is legal pluralism?" Journal of Legal Pluralism, $n^{\circ} 24,1986$, p. 1-55.

LECHTE, John. 50 Pensadores Contemporâneos Essenciais. Do Estruturalismo à Pós-Modernidade. Rio de Janeiro: Difel, 2002.

LÉVI-STRAUSS, Claude. O Olhar Distanciado. Lisboa, Ed. 70, 1986.

MALINOWSKI, Bronislaw. Crime e Costume na Sociedade Selvagem. Tradução: Maria Clara Corrêa Dias. 2. ed., Brasilia: UnB, 2008.

MONTEIRO, Washington de Barros. Curso de Direito Civil. vol. 3. São Paulo: Saraiva, 1997.

MOURA, Margarida Maria. Aspectos Políticos da obra de Franz-Boas. Conferência proferida no IAE-USP, em 5 de junho de 1992.

PANOFF, Michel; PERRIN, Michel. Dictionnaire de l'Etnologie. Paris: Petite Bibliotheque Payot, 1976.

RAMOS, Alcida Rita. Sociedades Indígenas. São Paulo: Ática, 1986.

ROULAND, Norbert. Anthropologie Juridique. Paris: Puf, 1990.

SHIRLEY, Robert W. Antropologia Jurídica. São Paulo: Saraiva, 1987.

TOURAINE, Alain. Igualdade e Diversidade. O Sujeito Democrático. Tradução: Modesto Florenzano. Bauru: Edusc, 1998. 